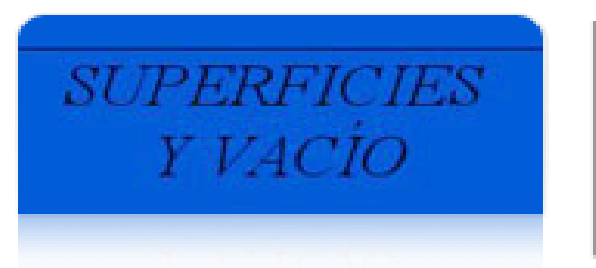

Superficies y vacío

ISSN: 1665-3521

alex@fis.cinvestav.mx

Sociedad Mexicana de Ciencia y Tecnología de Superficies y Materiales A.C.

México

Cheang Wong, J.C.; Díaz Valdés, E.; Jergel, M.; Morales, A.; Vargas, R.

Rutherford Backscattering analysis of Bi-based superconducting films

Superficies y vacío, núm. 9, diciembre, 1999, pp. 162-1654

Sociedad Mexicana de Ciencia y Tecnología de Superficies y Materiales A.C.

Distrito Federal, México

Available in: http://www.redalyc.org/articulo.oa?id=94200943

How to cite

Complete issue

- More information about this article

Journal's homepage in redalyc.org

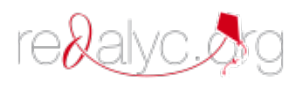

Scientific Information System Network of Scientific Journals from Latin America, the Caribbean, Spain and Portugal Non-profit academic project, developed under the open access initiative 


\title{
Rutherford Backscattering analysis of Bi-based superconducting films
}

\author{
J.C. Cheang-Wong \\ Instituto de Física, UNAM, A.P. 20-364, México 01000 D.F., México. \\ E. Díaz-Valdés \\ Escuela Superior de Física y Matemáticas-IPN, Edif. 9 UPALM, México 07738 D.F., México. \\ M. Jergel, A. Morales \\ Departamento de Física, CINVESTAV-IPN, A.P. 14-740, México 07000 D.F., México. \\ R. Vargas \\ Escuela Superior de Ingeniería Química e Industrias Extractivas-IPN, Edif. 7 UPALM, México 07738 D.F., México.
}

\begin{abstract}
The elemental composition, film thickness and concentration depth profiles of precursor and superconducting $(\mathrm{Bi}, \mathrm{Pb})-\mathrm{Sr}-$ $\mathrm{Ca}-\mathrm{Cu}-\mathrm{O}$ films were studied by the Rutherford Backscattering Spectrometry (RBS) technique. The precursor films were deposited on $\mathrm{MgO}$ single-crystalline substrates from an aerosol atomized ultrasonically from an aqueous nitrate solution. Precursor films, about 5 to $5.5 \mu \mathrm{m}$ thick, were then annealed in air at temperatures ranging from $835^{\circ} \mathrm{C}$ to $855^{\circ} \mathrm{C}$ during $10 \mathrm{~h}$. XRD studies revealed mainly the presence of the 2212 phase (for bulk $T_{\mathrm{c}}$ is about $85 \mathrm{~K}$ ). Films annealed at temperatures $\mathrm{T}_{\mathrm{a}} \geq 850^{\circ} \mathrm{C}$ were superconducting with $T_{\mathrm{c}}$ in the range of 60 to $71 \mathrm{~K}$, showing a double $T_{\mathrm{c}}$ onset at $85 \mathrm{~K}$ and $110 \mathrm{~K}$. The RBS study of the Bi-profile of precursors showed a maximum content of Bi at a depth around 1 to $2 \mu \mathrm{m}$ from the film surface. After the film annealing, the Bi content was found to be constant from the surface to about $1 \mu \mathrm{m}$ depth, decreasing then its value towards the film-substrate interface.
\end{abstract}

Keywords: Superconductors, Bi-based thin films, Rutherford Backscattering, spray pyrolysis.

\section{Introduction}

Ion Beam Analysis (IBA) techniques, such as Rutherford Backscattering Spectrometry (RBS) and Nuclear Reaction Analysis (NRA), have been largely used to study the composition and microstructure of $\mathrm{H} T_{\mathrm{c}}$ superconducting thin films [1,2]. In particular, we have used recently RBS to determine the elemental composition and concentration depth profiles of Tl-based superconducting films prepared by spray pyrolysis $[3,4]$. In the present paper we study the basic properties of a series of Bi-based films deposited on $\mathrm{MgO}$ singlecrystalline substrates from an aerosol atomized ultrasonically from an aqueous nitrate solution. Actually, the $(\mathrm{Bi}, \mathrm{Pb})_{2} \mathrm{Sr}_{2} \mathrm{Ca}_{2} \mathrm{Cu}_{3} \mathrm{O}_{10} / \mathrm{Ag}$ composite tapes belong currently to the most promising $\mathrm{H} T_{\mathrm{c}}$ superconductors for large-scale applications, namely for energy transmission devices $[5,6]$.

In particular, $\mathrm{Pb}$ doping in $\mathrm{Bi}-\mathrm{Sr}-\mathrm{Ca}-\mathrm{Cu}-\mathrm{O}$ superconductors has been widely reported to promote formation of the $\mathrm{Bi}_{2} \mathrm{Sr}_{2} \mathrm{Ca}_{2} \mathrm{Cu}_{3} \mathrm{O}_{10+\delta}(\mathrm{Bi}-2223)$ phase [7]. On the other hand, it was found that the $\mathrm{Bi}$ concentration is often non-uniform (less in the surface). However, in our case, for films having a uniform Bi concentration no clear improvement of $T_{\mathrm{c}}$ was reached.

The purpose of the present paper is to report on results of an investigation of Bi-concentration depth profiles of Bi-based superconducting films by means of the RBS method. Results of this investigation will be correlated with the film superconducting properties.

\section{Experimental}

A series of superconducting Bi-based films (Bi$\mathrm{Pb}-\mathrm{Sr}-\mathrm{Ca}-\mathrm{Cu}-\mathrm{O}$ ) were prepared by spray pyrolysis according to the 2-step procedure described in detail elsewhere [8]. First, an aerosol atomized ultrasonically from an aqueous nitrate solution of the $\mathrm{Bi}, \mathrm{Pb}, \mathrm{Sr}, \mathrm{Ca}$ and $\mathrm{Cu}$ components (with a cation ratio 2:0.6:2:2:3) was sprayed for 5 minutes onto single-crystalline $\mathrm{MgO}$ substrates heated to $250^{\circ} \mathrm{C}$. Three to five of such cycles were applied, leading to a total film thickness of about 5-5.5 $\mu \mathrm{m}$. These $\mathrm{Bi}-\mathrm{Pb}-\mathrm{Sr}-\mathrm{Ca}-\mathrm{Cu}-\mathrm{O}$ as-deposited precursor films were then annealed in air at temperatures ranging from 835 to $855^{\circ} \mathrm{C}$ for $10 \mathrm{~h}$ to become superconducting. Under these conditions, the complete decomposition of nitrates and an improvement of the chemical homogeneity of the synthesized films take place.

The superconducting state of the samples was detected by the critical temperature $T_{\mathrm{c}}$ value measurements, the microstructure, the chemical composition and the phase identification. The resistivity was measured by using the standard four-point resistive method with the $1 \mu \mathrm{V} / \mathrm{cm}$ criteria. The X-ray diffraction patterns and the phase composition were examined with the $\mathrm{CuK}_{\alpha}$ radiation using a D-500 Siemens diffractometer in the standard Bragg-Brentano $(\theta-2 \theta)$ geometry. The RBS measurements were carried out using the Instituto de Física $3 \mathrm{MV}$ accelerator (NEC 9SDH-2 Pelletron). 
Thus, we determined not only the elemental composition of the samples, but also the concentration depth profiles of the constituent atoms [1,9]. In the present work we used a $3.1 \mathrm{MeV}^{4} \mathrm{He}^{+}$beam to obtain the composition of both precursor and superconducting films. The concentration depth profiles were obtained by fitting the experimental spectra using the RUMP simulation program [10].

\section{Results and discussion}

The resistivity measurements were performed by the standard four-point method on Bi-based films annealed in air at five different temperatures $(835,840$, 845,850 and $855^{\circ} \mathrm{C}$ ). All the films were superconductors, except the one annealed at $835^{\circ} \mathrm{C}$. Fig. 1 shows the curves corresponding to the films annealed at 850 and $855^{\circ} \mathrm{C}$. The main feature of resistivity curves of the superconducting films is the presence of a double $T_{\mathrm{c}}$ onset at $85 \mathrm{~K}$ and $110 \mathrm{~K}$, which indicate the coexistence of two different Bi-based superconducting phases in the samples. Moreover, the critical temperature $T_{\mathrm{c}}(\mathrm{R}=0)$ seems to depend mainly on the annealing temperature $\mathrm{T}_{\mathrm{a}}$ Indeed, while the best $T_{\mathrm{c}}$ 's, in the range of 60 to $71 \mathrm{~K}$, were obtained for the films annealed at $\mathrm{T}_{\mathrm{a}} \geq 850^{\circ} \mathrm{C}$, no superconducting properties could be observed for films annealed at $\mathrm{T}_{\mathrm{a}} \leq 835^{\circ} \mathrm{C}$.

The X-ray diffraction pattern of the film annealed at $855^{\circ} \mathrm{C}$, giving the highest $T_{\mathrm{c}}$, may be seen in Fig. 2. The main diffraction lines assigned to the $\mathrm{Bi}_{2} \mathrm{Sr}_{2} \mathrm{Ca}_{1} \mathrm{Cu}_{2} \mathrm{O}_{8}(\mathrm{Bi}-2212)$ phase are indicated. However, it must be stressed that we are using the Bragg-Brentano configuration, and hence only diffractions from the planes parallel to the film surface can be observed. Therefore, other minor phases can be present, such as the Bi-2223, in agreement with the presence of a double $T_{\mathrm{c}}$ onset at $85 \mathrm{~K}$ and $110 \mathrm{~K}$ in the resistivity curves.

The tail observed in these curves may be due to the presence of the Bi-2201 phase, whose assigned lines are indicated in the diffraction pattern, since their intensities decrease with the increment of $T_{\mathrm{c}}$, thus showing its influence. On the other hand, it is important to notice that the crystallographic phase composition and the elemental chemical composition may differ from each other, sometimes even substantially, as confirmed in our previous experiments [3].

The sample composition as well as the concentration depth profiles of the constituent elements were determined from the RBS measurements. Fig. 3 shows the RBS spectra obtained with a $3.1 \mathrm{MeV}{ }^{4} \mathrm{He}^{+}$ beam from two superconducting films annealed during 10 hours at $850^{\circ} \mathrm{C}\left(T_{\mathrm{c}}=59 \mathrm{~K}\right)$ and at $845^{\circ} \mathrm{C}\left(T_{\mathrm{c}} \approx 58 \mathrm{~K}\right)$. The RBS results show that the superconducting films mainly have a $(\mathrm{Bi}, \mathrm{Pb})_{\mathrm{X}} \mathrm{Sr}_{1.4} \mathrm{Ca}_{1} \mathrm{Cu}_{1.5} \mathrm{O}_{8+\delta} \quad$ chemical composition, with $x$ varying from $x=2$ at the surface region and then decreasing with depth.

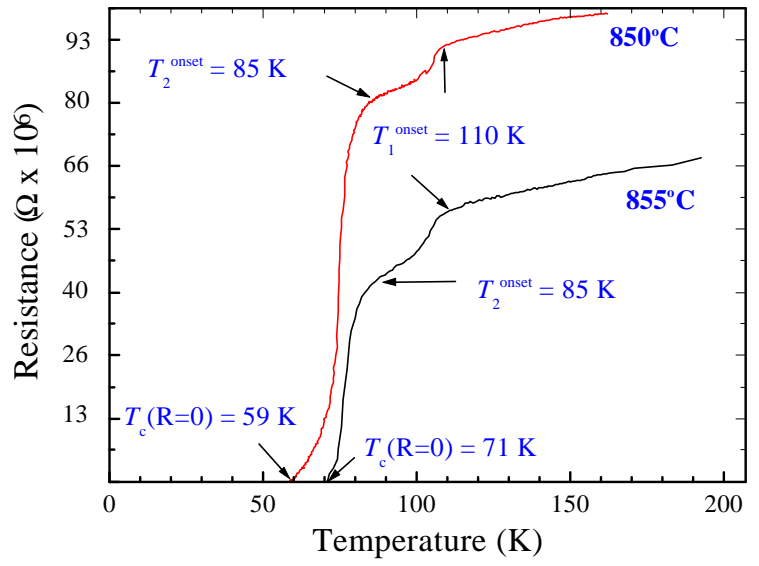

Fig. 1.Resistivity $v s$ temperature curves corresponding to the Bi-based superconducting films annealed in air at 850 and $855^{\circ} \mathrm{C}$.

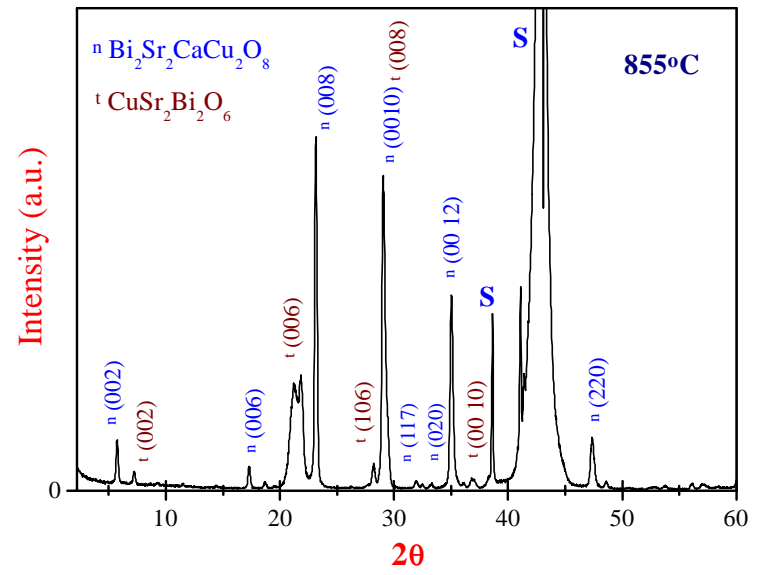

Fig. 2. XRD pattern of the Bi-based superconducting film annealed at $855^{\circ} \mathrm{C}$. The identified diffraction peaks for the Bi$2212(n)$ and $\mathrm{Bi}-2201(t)$ phases are indicated, as well as for the $\mathrm{MgO}$ substrate $(\mathrm{S})$.

At this point, it is important to stress that with RBS we can not accomplish the accurate determination of the $\mathrm{Bi}$ and $\mathrm{Pb}$ concentrations independently, because the contribution of $\mathrm{Bi}$ and $\mathrm{Pb}$ atoms to the RBS spectrum can not be distinguished from each other. However, recent studies concerning the effect of $\mathrm{Pb}$ in Bi-based superconductors demonstrate that $\mathrm{Pb}$ doping promote not only the formation of the $\mathrm{Bi}_{2} \mathrm{Sr}_{2} \mathrm{Ca}_{2} \mathrm{Cu}_{3} \mathrm{O}_{10+\delta}$ phase [11], but does not affect the critical temperature [12]. Therefore, for convenience, the $(\mathrm{Bi}, \mathrm{Pb})_{\mathrm{X}}$ concentration will be referred to here after just as the $\mathrm{Bi}$ concentration. In order to accomplish the best RBS simulation for all the Bi-based films we assumed that the ratio of the $\mathrm{Sr}, \mathrm{Ca}$, $\mathrm{Cu}$ and $\mathrm{O}$ constituents does not change as a function of depth, i.e., $\mathrm{Sr}: \mathrm{Ca}: \mathrm{Cu}: \mathrm{O}=1.4: 1: 1.5: 8$, but only the $\mathrm{Bi}$ concentration does. This assumption is sustained on the fact that calcium and/or bismuth are the most likely diffusing 


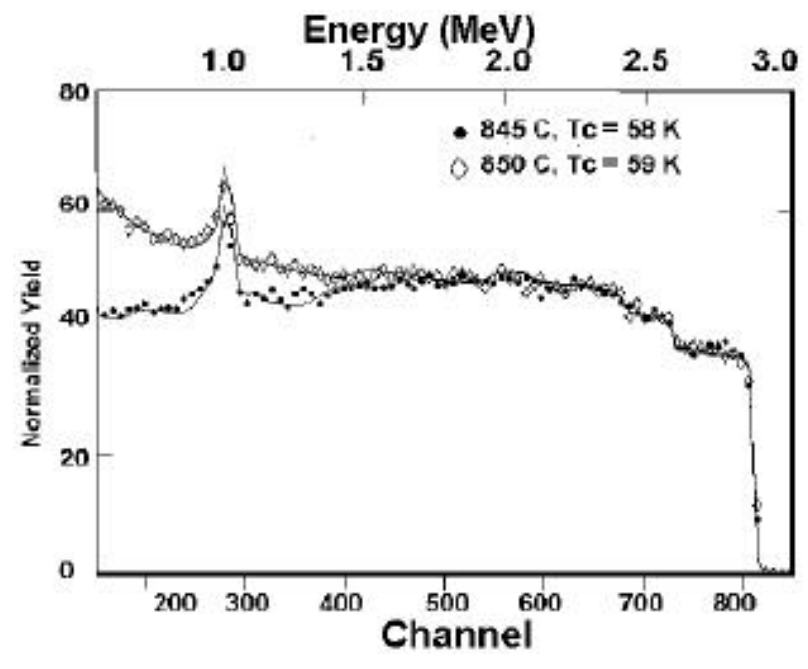

Fig. 3. $3.1 \mathrm{MeV}{ }^{4} \mathrm{He}^{+}$RBS spectra obtained from two Bibased superconducting films annealed at $850^{\circ} \mathrm{C}\left(T_{\mathrm{c}}=59 \mathrm{~K}\right)$ and at $845^{\circ} \mathrm{C}\left(T_{\mathrm{c}} \approx 58 \mathrm{~K}\right)$. The solid line represents the RUMP simulation.

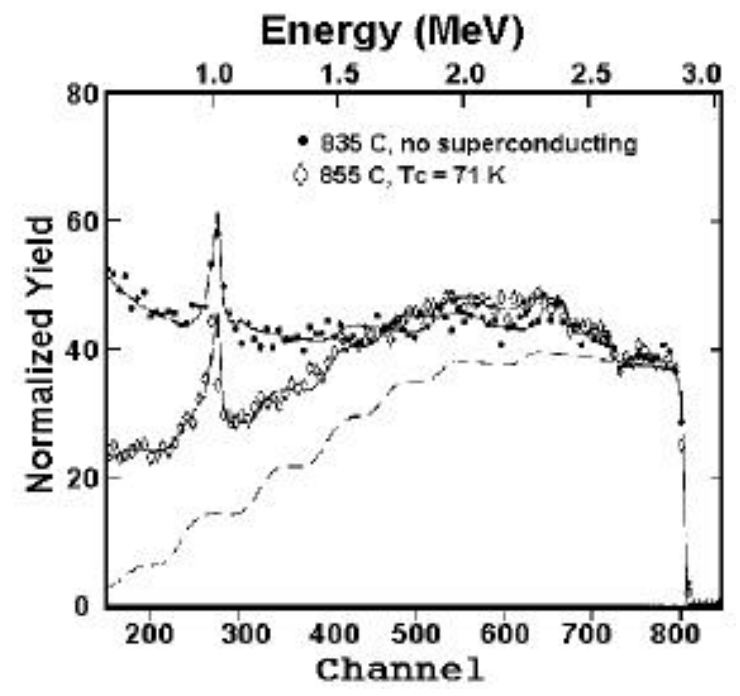

Fig. 4. $\quad 3.1 \mathrm{MeV} \quad{ }^{4} \mathrm{He}^{+}$RBS spectra obtained from a superconducting film annealed at $855^{\circ} \mathrm{C}$ (the highest $T_{\mathrm{c}}=71 \mathrm{~K}$ ) and from a Bi-based film annealed at $835^{\circ} \mathrm{C}$ (not superconducting). The RUMP simulation is included (-), together with the contribution of $\mathrm{Bi}$ atoms to the RBS spectrum of the superconducting film (----).

species in Bi-based films [13]. Moreover, the effect of a small change in $\mathrm{Bi}$ content has more significance on the RBS simulated spectrum than a similar or larger deviation in $\mathrm{Ca}$ content does, because the contribution of each element to the RBS spectrum depends on the square of the atomic number. According to the RUMP simulation (Fig. 3), the film annealed at $850^{\circ} \mathrm{C}$ exhibits the most homogeneous $\mathrm{Bi}$ concentration as a function of depth compared with the other studied samples. However, its critical temperature $T_{\mathrm{c}}$ is essentially the same that those of the film annealed at $845^{\circ} \mathrm{C}$
Therefore, it seems that the behavior of the $\mathrm{Bi}$ concentration depth profiles does not affect significantly the $T_{\mathrm{c}}$. Actually, the $\mathrm{Bi}$ concentration is often nonuniform in Bi-based film, but for films having a uniform Bi concentration no clear improvement of $T_{\mathrm{c}}$ was attained [14].

We would like to insist on this fact by showing in Fig. 4 the RBS spectra obtained from a superconducting film annealed at $855^{\circ} \mathrm{C}$ (with the highest $T_{\mathrm{c}}=71 \mathrm{~K}$ ) and from a Bi-based film annealed at $835^{\circ} \mathrm{C}$ (not superconducting). It is clear that a more uniform $\mathrm{Bi}$ concentration profile is observed for the nonsuperconducting film. The dashed line in Fig. 4 represents the contribution of $\mathrm{Bi}$ atoms to the $\mathrm{RBS}$ spectrum of the superconducting film.

Moreover, we investigated the content and depth profiles of bismuth for samples annealed at different temperatures, up to the depth of 5-6 $\mu \mathrm{m}$ from the film surface, using the $3.1 \mathrm{MeV}{ }^{4} \mathrm{He}^{+}$RBS spectra. Fig. 5 shows the Bi-concentration depth profiles of the superconducting Bi-based films annealed at different temperatures, and no evident dependence of the physical properties, mainly $T_{\mathrm{c}}$, on the Bi-concentration profiles can be asserted. Indeed, the Bi content of all the Bi-based superconductors was found to be constant $\left(\mathrm{Bi}_{X=2}\right)$ from the film surface up to a depth of about $3 \mu \mathrm{m}$, where the Bi-concentration depth profiles decreased towards the film-substrate interface.

In order to study the effect of the annealing of the precursor films on the Bi-concentration profiles, RBS measurements were performed on Bi-based films before and after the annealing. Fig. 6 shows the $\mathrm{Bi}-$ concentration depth profiles of a Bi-based film before (not superconducting) and after an annealing at $855^{\circ} \mathrm{C}$ $\left(T_{\mathrm{c}}=71 \mathrm{~K}\right)$. Before annealing, the Bi-profile presents a rounding shape with a maximum $\mathrm{Bi}$ content at around 1 $\mu \mathrm{m}$ from the film surface and a plateau in the region $2-4 \mu \mathrm{m}$. Moreover, the main feature observed on precursor films is a lacking of $\mathrm{Bi}$ atoms at the surface region (from the film surface up to $\sim 1 \mu \mathrm{m}$ ). This $\mathrm{Bi}$ deficiency is overcome after the annealing treatment in air at different temperatures. Indeed, after the annealing, the $\mathrm{Bi}$ content is constant from the film surface up to a depth of about $2 \mu \mathrm{m}$, and then it decreases towards the film-substrate interface (see Fig. 5).

From the results shown in Fig. 1 and Fig. 2 we may observe that the highest $T_{\mathrm{c}}$ values and the best crystallographic orientations of Bi-based films are obtained after relatively high annealing temperatures $\mathrm{T}_{\mathrm{a}} \geq 850^{\circ} \mathrm{C}$.

Also, from the point of view of the Bi content, there is a well defined plateau up to about $2 \mu \mathrm{m}$ from the film surface, giving apparently a relatively optimum $\mathrm{Bi}$ content $\left(\mathrm{Bi}_{X=2}\right)$ in the depth profile of superconducting films. From the presented results it seems that a correlation exists between the annealing temperature $\mathrm{T}_{\mathrm{a}}$ and the critical temperature $T_{\mathrm{c}}(\mathrm{R}=0)$, and that $\mathrm{T}_{\mathrm{a}} \geq 850^{\circ} \mathrm{C}$ are required for synthesize $\mathrm{Bi}$-based films with good 


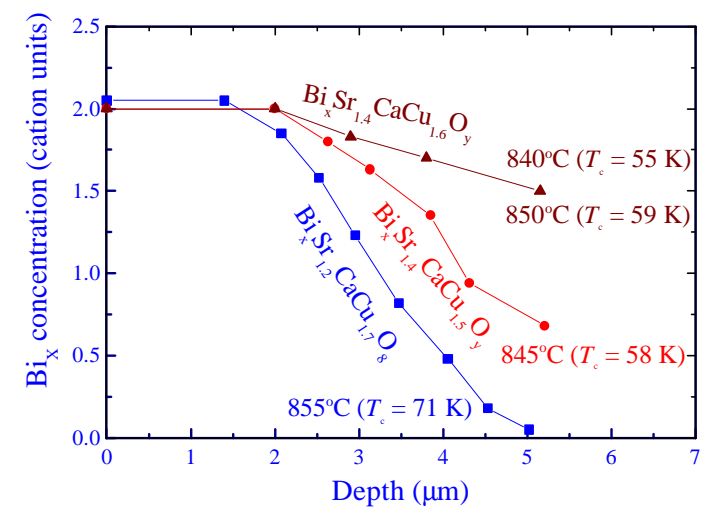

Fig. 5. Bi-concentration depth profiles of the superconducting Bi-based films annealed at different temperatures. Profiles were obtained from the RUMP simulation of the $3.1 \mathrm{MeV}^{4} \mathrm{He}^{+} \mathrm{RBS}$ spectra.

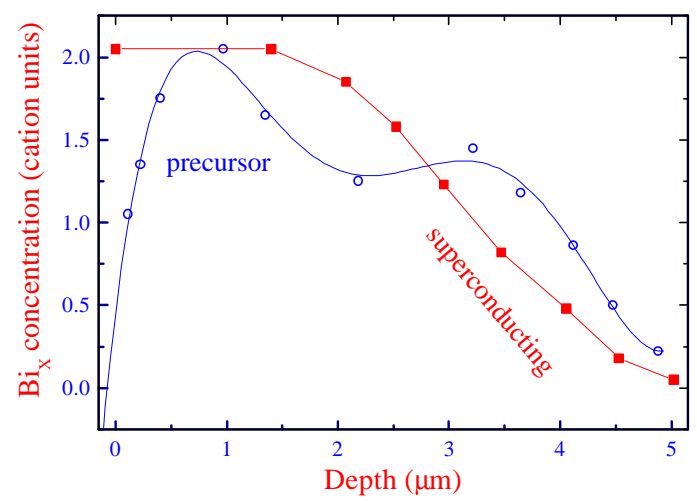

Fig. 6. Bi-concentration depth profiles of a Bi-based film before (not superconducting) and after an annealing at $855^{\circ} \mathrm{C}$ $\left(T_{\mathrm{c}}=71 \mathrm{~K}\right)$.

superconducting and microstructural properties. However, at the moment we can not establish a clear relationship between the Bi-concentration depth profiles and the physical properties of Bi-based superconducting films. The only evidence we have is that good superconducting films are obtained, after annealing, when the Bi content seems to approach its stoichiometric value $\left(\mathrm{Bi}_{X=2}\right)$ at the near-surface region.

\section{Conclusion}

By means of RBS measurements we have determined the elemental composition and the concentration depth profiles of Bi-based superconducting films. By investigating also the reference precursor films we conclude that the $\mathrm{Bi}$ concentration varies as a function of depth and depends on the annealing temperature. Before the annealing, the Bi-concentration depth profiles showed a maximum at around $1 \mu \mathrm{m}$ from the film surface, but there is a clear Bi deficiency at the surface region.
As a consequence of annealing, the mobility of $\mathrm{Bi}$ atoms in the film increases and therefore a uniform $\mathrm{Bi}$ content up to about $2 \mu \mathrm{m}$ from the film surface is obtained, giving apparently a relatively optimum $\mathrm{Bi}$ content $\left(\mathrm{Bi}_{X=2}\right)$ in the depth profile of superconducting films.

\section{Acknowledgments}

The authors acknowledge K. López and F.J. Jaimes for accelerator operation, Dr. Matej Jergel for his helping in XRD measurements and the technical assistance on films deposition of J. García-Coronel. This work was supported by CONACyT under contracts G0010-E and F036-E9109.

\section{References}

[1] L.E. Rehn, Nucl. Instr. and Meth. B 64, 161 (1992).

[2] J. Siejka, Nucl. Instr. and Meth. B 85, 216 (1994).

[3] J.C. Cheang-Wong, M. Jergel, E. Andrade, C. Falcony, A. Morales, A. Conde-Gallardo. Nucl. Instr. and Meth. B 136-138, 1300 (1998).

[4] E. Andrade, M. Jergel, J.C. Cheang-Wong, A. CondeGallardo, C. Falcony, Nucl. Instr. and Meth. B 122, 677 (1997).

[5] D.P. Hampshire, S.S. Oh, K. Osamura, D.C. Larbalestier, Supercond. Sci. Technol. 3, 560 (1990).

[6] G. Grasso, R. Flukiger, Supercond. Sci. Technol. 10, 223 (1997).

[7] S.M. Green, C. Jiang, Y. Mei, H.L. Luo, C. Politis, Phys. Rev. B 38, 5016 (1988).

[8] M. Jergel, Supercond. Sci. Technol. 8, 67 (1995).

[9] W.K. Chu, J.W. Mayer, M.A. Nicolet, Backscattering Spectrometry, (Academic Press, New York, 1978).

[10] L.R. Doolittle, Nucl. Instr. and Meth. B 9, 344 (1985).

[11] A.L. Crossley, Y.H. Li, A.D. Caplin, J.L. MacManusDriscoll, Physica C 314, 12 (1999).

[12] E. Díaz-Valdés, F. Jiménez-Tovar, M. Jergel, C. FalconyGuajardo, F. Morales-Leal, these proceedings.

[13] J.M. Tarascon, Y. LePage, L.H. Greene, B.G. Bagley, P. Barboux, D.M. Hwang, G.W. Hull, W.R. McKinnon, M. Giroud, Phys. Rev. B 38, 2504 (1988).

[14] N. Matsunami, O. Onoue, M. Noguchi, J. Nozaki, Y. Takai, Nucl. Instr. and Meth. B 136-138, 1291 (1998). 